\title{
Selective Non Operative Management of Blunt Liver Trauma: Is It Still a Challenge?
}

\section{Mohammed Abdallah Hablus, Amir Fawzy Abdelhamid, Mahmoud Mostafa Alsherief, Osama Hasan Abd-Raboh}

General Surgery Department, Faculty of Medicine, Tanta University Hospital, Tanta, Egypt

\section{Email address:}

mahablus@yahoo.com (M. A. Hablus)

\section{To cite this article:}

Mohammed Abdallah Hablus, Amir Fawzy Abdelhamid, Mahmoud Mostafa Alsherief, Osama Hasan Abd-Raboh. Selective Non Operative Management of Blunt Liver Trauma: Is It Still a Challenge? Journal of Surgery. Vol. 5, No. 6, 2017, pp. 93-96. doi: $10.11648 /$ j.js. 20170506.12

Received: September 18, 2017; Accepted: October 8, 2017; Published: November 10, 2017

\begin{abstract}
The non-therapeutic laparotomy in managing cases with blunt liver injuries is not without risks, so selective nonoperative treatment in stable patients was tried in many centers and has become the standard of care of these patients The aim of this study was to assess the feasibility and safety of selective non-operative management of blunt liver injury in our institution Patients and Methods: This prospective study was conducted on 40 patients with blunt liver injury who met our inclusion criteria admitted to Tanta University Hospital during the period from January 2012 to January 2014. All patients were treated by selective non-operative treatment (repeated clinical examination, serial U/S and CT study and follow up) Results: The age of our patients ranged from 26 to 40 years with a mean $( \pm \mathrm{SD})$ of $31.3 \pm 3.77$ years. 36 patients were males $(90 \%)$, while 4 patients $(10 \%)$, were female. Total length of stay was ranged from 2 days to 15 days with a mean $( \pm \mathrm{SD})$ of $5.8 \pm 3.27$ days as regards all cases. Intensive care unit stay was in 2 cases $(5 \%)$ which FNOM with mean $( \pm \mathrm{SD})$ of $1.5 \pm 0.7$ days. CT study was done in all cases (100\%), 2 cases $(5 \%)$ was operated after 6 hours of conservatism in ICU due to hemodynamic instability after initial assessment of stability. Conclusions: Selective non operative management of blunt liver injury in bunt abdominal trauma is safe, efficient, and cost-effective in the appropriate clinical setting and can lead to fewer unnecessary laparotomies in patients with liver injury. Proper patient selection, resources that permit close observation, and frequent abdominal examinations are paramount in obtaining the best results.
\end{abstract}

Keywords: Selective Non-operative Management, Radiological Grading, Blunt Liver Trauma

\section{Introduction}

Liver is the most commonly injured organ following blunt abdominal trauma [1,2]. Blunt liver trauma accounts for 15$20 \%$ of abdominal trauma [3]. The prevalence of liver injuries has increased during the past three decades. Initially, due to war actions and secondly as a result urban accidents, this together with better diagnosis through the liberal use of computed tomography $(\mathrm{CT})$ and advanced trauma treatment modalities $[4,5]$.

The advent of improved and expeditious imaging technologies for the diagnosis and treatment of solid organ injuries, accompanied by advances in critical-care monitoring, prompted a paradigm shift toward non operative management (NOP) for treatment of solid-organ injuries.
Subsequently, the shift toward non-operative management yielded a decrease in total mortality rates [4].

The advantages of non-operative management includes avoidance of non therapeutic laparotomies, less intra-abdominal and general postoperative complications, decreased blood transfusion requirements, and decreased hospital stay. [6].

Selective non operative management and the use of angioembolization is now the standard of care of hepatic trauma [7].

Failure of NOP (FNOP) is defined as the need for a laparotomy to be performed more than six hours after hospital admission [8].

\section{Aim of the Work}

The aim of this study was to assess the feasibility and safety of NOP of blunt liver injury in our institution. 


\section{Patients and Methods}

This prospective study was conducted on 40 patients with blunt Liver injury who met our inclusion criteria admitted to Tanta University Hospital during the period from January 2012 to January 2014.

Adult patients more than 15 years old from both sexes with blunt abdominal trauma associated with blunt liver injury were included in our study. All patient charts were reviewed concerning mechanism of injury, initial Management, associated injuries, grade of liver injury, quantity of haemoperitoneum, treatment, Blood products received, total length of stay (LOS), days in the intensive care unit (ICU), complications and mortality.

Selection criteria:

Hemodynamic stability:

Good volume pulse.

Rate less than 100 beats per minute.

Systolic blood pressure of more than $90 \mathrm{mmHg}$.

No demonstrable peritoneal signs on abdominal examination.

The absence of any intraperitoneal or retroperitoneal injuries on computerized axial tomography scans requiring operative intervention.

When the initial decision could not safely be established from findings in the patient charts, failure of NOM (FNOM) was defined as a laparotomy performed more than $6 \mathrm{~h}$ after admission.

An informed consent was taken from the participants after explaining the predicted risks and the advantages of this approach, also the ethical committee of our institution was approved.

All patients included in the study were subjected to:

Full history taking, Complete clinical examination, Serial vital data follow up, Laboratory investigations including:

a. Hemoglobin level. b. SGPT, SGOT level.

Imaging including:

Serial abdominal and pelvic ultrasound.

CT Abdomen and pelvis. with oral and intravenous contrast is the cornerstone investigation and was performed in every case.

Treatment consists of:
Admission in ICU or Surgical ward if there is no available places in the ICU.

Nothing per mouth for 24 hours.

IV fluids guided by vital signs and urine output

Blood products transfusion after cross matching.

IV Broad spectrum antibiotics and IV metronidazole.

Urgent laparotomy considered if there is significant drop in hemoglobin level associated with increase amount of intra peritoneal free fluid and air under diaphragm or development of signs of peritonitis or hemodynamic instability.

Follow up of all cases after discharge.

Statistics

Statistical presentation and analysis of the present study was conducted, using the mean, standard deviation and chisquare test by SPSS V.16.

\section{Results}

Our study includes Forty patients with blunt liver injury after blunt abdominal trauma.

The age of our patients ranged from 26 to 40 years with a mean $( \pm \mathrm{SD})$ of $31.3 \pm 3.77$ years. 36 patients were males $(90 \%)$, while 4 patients $(10 \%)$, were female.

Total length of stay was ranged from 2 days to 15 days with a mean $( \pm \mathrm{SD})$ of $5.8 \pm 3.27$ days as regards all cases.

Intensive care unit stay was in 2 cases $(5 \%)$ which FNOM with mean $( \pm \mathrm{SD})$ of $1.5 \pm 0.7$ days.

CT study was done in all cases $(100 \%), 2$ cases (5\%) was operated after 6 hours of conservatism in ICU due to hemodynamic instability after initial assessment of stability.

The CT findings were as follow:

Grades of liver injury:

Grade (I) (contusion): 6 cases

Grade II: 16 cases.

Grade III: 14 cases.

Grade IV: 4 cases

Two cases with renal injuries.

Two case with splenic contusion.

sixteen cases with rim haemoperitoneum.

Four cases with left liver lobe injury.

thirty six cases with right liver lobe injury.

Laboratory data:

Table 1. Shows laboratory data of the study population.

\begin{tabular}{llll}
\hline & & Range & Mean \pm SD \\
\hline \multirow{2}{*}{$\mathrm{Hb}$} & Initial & $8-13$ & $11.05 \pm 1.17$ \\
& $12 \mathrm{hr}$ & $9-13$ & $12.12 \pm 0.63$ \\
$\mathrm{SGOT}$ & Initial & $350-950$ & $599.5 \pm 132.3055$ \\
& $12 \mathrm{hr}$ & $250-720$ & $459 \pm 115.9267$ \\
$\mathrm{SGPT}$ & Initial & $350-900$ & $584.25 \pm 128.2115$ \\
& $12 \mathrm{hr}$ & $240-600$ & $327.75 \pm 81.79968$ \\
\hline
\end{tabular}

Outcome:

Table 2. Shows outcome of the conservative treatment the study population.

\begin{tabular}{lll}
\hline & Outcome & \\
\cline { 2 - 3 } & Number & Percentage \\
\hline Success & 38 & $95 \%$ \\
Failure & 2 & $5 \%$ \\
\hline
\end{tabular}


Table 3. Shows relation between grades of injury and outcome of the conservative treatment.

\begin{tabular}{lllll}
\hline \multirow{2}{*}{ Grade } & & Outcome & Failure & Total \\
\cline { 2 - 5 } & Success & - & 6 \\
Grade I & $\mathrm{N}$ & 6 & - & $100.0 \%$ \\
& $\%$ & $15 \%$ & - & 16 \\
Grade II & $\mathrm{N}$ & 16 & - & $100.0 \%$ \\
& $\%$ & $40 \%$ & - & 14 \\
Grade III & $\mathrm{N}$ & 14 & - & $100.0 \%$ \\
& $\%$ & $35 \%$ & 2 & 4 \\
Grade IV & $\mathrm{N}$ & 2 & $5 \%$ & $100.0 \%$ \\
& $\%$ & $5 \%$ & $5 \%$ & 40 \\
Total & $\mathrm{N}$ & 38 & & $100.0 \%$ \\
X2 & $\%$ & $95 \%$ & & \\
P. value & 19.998 & & & \\
\hline
\end{tabular}

P. value $<0.05$ (significant).

Table 4. Shows relation between initial: Hb level, systolic blood pressure, pulse and outcome of the conservative treatment.

\begin{tabular}{lllll}
\hline & Success & Failure & t. test & P. value \\
\hline Initial Hb & $11.3 \pm 0.89$ & $8.75 \pm 0.75$ & 4.47 & 0.001 \\
Initial systolic BLP & $113.88 \pm 5.9$ & $75 \pm 15$ & 3.63 & 0.0002 \\
Initial Pulse & $83.05+4.45$ & $110 \pm 10$ & 3.76 & 0.0004 \\
\hline
\end{tabular}

P. value $<0.05$ (significant).

Table 5. Shows relation between initial and after $12 \mathrm{hr}$ SGPT, SGOT and outcome of the conservative treatment.

\begin{tabular}{|c|c|c|c|c|}
\hline Outcome & & Mean + SD & t. test & P. value \\
\hline Initial SGPT & $\begin{array}{l}\text { Success } \\
\text { Failure }\end{array}$ & $\begin{array}{l}554.72+96.27 \\
850+50\end{array}$ & 7.02 & 0.00074 \\
\hline $12 \mathrm{hr}$ SGPT & $\begin{array}{l}\text { Success } \\
\text { Failure }\end{array}$ & $\begin{array}{l}301.94+24.44 \\
560+40\end{array}$ & 8.94 & $2.8 \times 10-11$ \\
\hline Initial SGOT & $\begin{array}{l}\text { Success } \\
\text { Failure }\end{array}$ & $\begin{array}{l}567.77+94.43 \\
885+65\end{array}$ & 6.21 & 0.00035 \\
\hline $12 \mathrm{hr}$ SGOP & $\begin{array}{l}\text { Success } \\
\text { Failure }\end{array}$ & $\begin{array}{l}431.66+86.23 \\
705+15\end{array}$ & 11.9 & 0.00048 \\
\hline
\end{tabular}

P. value $<0.05$ (Significant).

\section{Discussion}

Non operative management for blunt hepatic trauma involves monitoring and radiological intervention, including angio-embolization [10].

In critical care units, patients undergo a protocol for intensive monitoring and an experienced surgical team must follow the patient closely [11].

The goal of NOM is to avoid unnecessary laparotomy which is not free of complications in selected patients with blunt abdominal injury [12]. The age of our patients ranged from 26 to 40 years with a mean $( \pm \mathrm{SD})$ of $31.3+3.77$ years. Most of them were males (90\%). Repeated physical examinations are the mainstay of management, also repeated abdominal ultrasound, and CT study were the available diagnostic tools in our study.

Peitzman et al., [3] stressed on the value of repeated physical examination as the patient may be in shock and the physiological mechanisms specially in adults may give a false impression at the start that the patient is stable, and stated that observation periods over 24 hours are rarely required.

In our study the patients were examined physically once every 2 hours for the 1 st 12 hours then once every 6 hours for the next day then once every 12 hours for the next 2 days, FAST scan also was done every 6 hours during the 1st day of admission then every 12 hours for the next days of admission, CBC, SGOT and SGPT were done every 12 hours.

In our study, 40 patients with blunt liver injury met our inclusion criteria. The conservative non operative treatment succeeded in $95 \%$ of cases while failed in $5 \%$ of cases.

Christmas et al, [2] has states that Non-operative management (NOM) has become the first treatment of choice when possible in patients with blunt liver trauma.

A policy of selective non-operative management (SNOM) has been accepted for blunt trauma in most trauma centers and this idea was accepted also for the stab wounds in the last two decades, but now it well established [13].

In our work, 2 patients had liver injury (Grade IV) operated after 6 hours while 2 cases treated by NOM.

Christmas et al., [2] suggested that grade IV liver injury can not success fully be managed non-operatively

Oral feeding was resumed after 24 hours in persistently stable patients as this is the consensus time for observation before feeding mentioned [14].

Most protocols, however, recommend evaluation of the 
patient over 24-72 hours [15].

In our study, initial $\mathrm{Hb}$ was ranged from 8 to $11 \mathrm{gm} / \mathrm{dl}$ with a mean $(+\mathrm{SD})$ of $11.05+1.17 \mathrm{gm} / \mathrm{dl}$, while after the $1^{\text {st }} 12$ hours $\mathrm{Hb}$ was ranged from 9 to $13 \mathrm{gm} / \mathrm{dl}$ with a mean $( \pm \mathrm{SD})$ of $12.12+0.63 \mathrm{gm} / \mathrm{dl}$.

This is in agreement with results obtained by (Ali et al.,[16]. who found that conservative treatment will be successful if initial $\mathrm{Hb}$ level not less than $10 \mathrm{gm} / \mathrm{dl}$ and show no drop in the $1^{\text {st }} 12$ hours

In our study, initial SGOT was ranged from 350 to $950 \mathrm{IU} / \mathrm{L}$ with a mean $( \pm \mathrm{SD})$ of $599.5 \pm 132.3055 \mathrm{IU} / \mathrm{L}$, while after the $1^{\text {st }} 12$ hours was ranged from 250 to 720 with a mean $( \pm \mathrm{SD})$ of $459 \pm 115.9267 \mathrm{IU} / \mathrm{L}$, and initial SGPT was ranged from 350 to $900 \mathrm{IU} / \mathrm{L}$ with a mean $( \pm \mathrm{SD})$ of $584.25 \pm 128.2115 \mathrm{IU} / \mathrm{L}$, while after the $1^{\text {st }} 12$ hours was ranged from 240 to $600 \mathrm{IU} / \mathrm{L}$ with a mean $(+\mathrm{SD})$ of $327.75 \pm 81.79968 \mathrm{IU} / \mathrm{L}$.

In our work we focused on SGPT and SGOT only as liver enzymes this is in agreement with results obtained by Friedmann [13].

In our work, Hospital stay was ranged from 2 to 15 days with a mean $( \pm \mathrm{SD})$ of $5.8 \pm 0.7$ days.

This is in agreement with that results obtained by Anderson et al [17] who found that the hospital stay was significantly less in the observation group than the operative group, and stated that this is helpful because patients can return to their normal life earlier and also it might decrease the financial costs.

The benefits of non-operative management of blunt liver injuries should be weighed against possible risks of delayed operation [18]. Also the key for success is the frequent clinical examination and patient monitoring as stated by Bhavinder K. et al; 2016 [19].

In our work, there was no delay in operative management of failed cases. Also, there was no mortality or complications in the setting of the operation or in the follow up.

\section{Conclusions}

Selective non operative management of blunt liver injury in bunt abdominal trauma is safe, efficient, and cost-effective in the appropriate clinical setting and can lead to fewer unnecessary operations in patients with liver injury. Proper patient selection, resources that permit close observation, and frequent abdominal examinations are paramount in obtaining the best results.

\section{References}

[1] Ahmed N, vernik JJ. Management of liver trauma in adults. J of Emergencies, Trauma and Shock 2011; 4: 114-9.

[2] Christmas AB, Wilson AK, Manning $B$ et al. selective management of blunt hepatic injuries including non-operative management is a safe and effective strategy. Surgery 2005; 138 (4): 606-10.

[3] Peitzman AB, schwab CW, yealy DM et al. the trauma manual: Trauma and active care surgery. Lippincott Manuel series (formly known as the spiral manual series) 2012; $4^{\text {th }}$ ed.

[4] Richordson HD, Granklin GA, hekon K I, et al. Evolution in the management of hepatic trauma: 25 year perspective. Ann Surg. 2000; 232: 324-30.

[5] Lucas CE, ledgerwood AN. Changing times and treatment of liver injury. Ann Surg. 2000; 66: 337-41.

[6] Eastern Association for surgery of trauma. Practice management guidelines for the non operative management of blunt injury to the liver and spleen. 2003. Available at: http://www.east.org.accessed February 2005.

[7] Kory S, Anita R, Skondorajah, et al. changing in the management of liver trauma leading to reduced mortality: 15 year experience in a major trauma centre ANZ J Surg. 2016; 86: 894-99.

[8] Nirman G, Tingstedt B, Ekelund $\mathrm{M}$, et al. Non-operative management of blunt liver trauma feasible and safe also in centers with a low trauma incidence. HPB2009; 11: 50-6.

[9] Moore EE, Cogbilt TH, Jurkowich GJ. Et al, organ injury scaling: spleen and liver (1994 revision) American Association of Surgery of Trauma J of Trauma 1995; 38: 323 4.

[10] Asensio JA, Roldan G, Petrone P, et al. operative and outcome in 103 AAST-OIS grades IV and V complex hepatic injuries. Journal of trauma 2003; 54: 647-53.

[11] Buccoliero F, Ruscelli P.: Current trends in polytrauma management. Diagnostic and the rapeutic algorithms operational in the trauma centre of Cesena, Italy. Annali Italiani di chirurgia 2010; 81: 81-93.

[12] Eastridge BJ Salinas J Schneider M, et al, Hypotension begins at $110 \mathrm{~mm} \mathrm{Hg}$ redefining "hypotension" wuth data. Journal of trauma 2007; 63: 291-97.

[13] Friedmann P. (2011): Selective management of stab wounds to the abdomen. Arch Surg 1968; 96: 292-295. Quated from JansenJO, Inaba K, Rizoli SB, et al; Selective non-operative management of penetrating abdominal injury in Great Britainand Ireland: survey of practice. Injury, Int. J. Care Injured; 4639: 1-6.

[14] Clark D. L., thombson S. R., Madiba T. E. et al (2005): Selective conservation in trauma management: a south African contribution. World J Surg. 29(8): 962-965.

[15] Navsaria P. H., Berli J. U. et al. (2007): Non-operative management of abdominal stab wounds- an analysis of 186 patients. S Afr J Surg; 45(4): 128-132.

[16] Ali N. K., Hemant V., Sumatra M. D. and Muthusamy C. (2009):

[17] Anderson I. E., Saghier M., Kneteman N. M. and Bigam D. L. (2004): Liver trauma: management of devascularization injuries. J. Trauma; 57: 1099-104.

[18] Stawichi S. P. (2007): Trends in nonoperative management of traumatic injuries: S synopsis. OPUS 12 scientist; 1 (1): 1935 .

[19] Bhavinder K. Arora, Rachit Arora, Akshit Arora (2016): Conservative treatment of blunt hepatic trauma: my experience. International Surgery Journal: 3(4) 2155-2159. 